\title{
Educação Integral como política pública de acesso à Educação Ambiental Patrimonial ${ }^{1}$
}

\author{
Educación Integral como política pública de acceso a la Educación \\ Ambiental Patrimonial
}
Integral Education as a public policy of access to Heritage Environmental Education

\author{
Célia Souza da Costa ${ }^{2}$
}

\begin{abstract}
Resumo
A educação integral é uma política pública que aos poucos vem sendo incorporada na educação brasileira, o que gera transformações nas práticas pedagógicas, no currículo escolar e nos espaços de ensino e aprendizagem. Neste cenário, a escola abre possibilidades, para que além das disciplinas obrigatórias, também sejam oferecidas aos alunos oportunidades de conhecer, discutir e refletir sobre diversas temáticas, dentre elas está a Educação Ambiental Patrimonial. Portanto, o objetivo deste trabalho é discutir como a educação integral possibilita o desenvolvimento paradigmático e prático da educação ambiental patrimonial. Deste modo, a metodologia utilizada foi a pesquisa qualitativa de cunho bibliográfico, documental exploratório e de análise reflexiva. Para conceituar e refletir sobre a educação ambiental patrimonial foram eleitos os autores Marchette (2016), Florêncio et al. (2014), Florêncio (2015) e Riffel (2017). No âmbito da educação integral, analisamos documentos oficiais do Ministério da Educação e Cultura (MEC) e contextualizamos essas informações com o aporte teórico apresentado por Pestana (2014) e Pinho e Peixoto (2017). Ademais, a pesquisa ressalta a importância da educação ambiental patrimonial no contexto escolar que exerce um papel fundamental na construção de um indivíduo social e ambiental, pois é por meio de atividades específicas da educação ambiental patrimonial que o discente aprimora a sua identidade cultural, as questões de pertencimento, do cuidado, de conservação e de preservação dos bens materiais e imateriais que se constituem enquanto patrimônio cultural.
\end{abstract}

Palavras-Chave: Educação Ambiental Patrimonial; Espaços de Ensino e Aprendizagem; Educação Integral. Política Pública.

\section{Resumen}

La educación integral es una política pública educativa que poco a poco viene siendo incorporada en la educación brasileña, lo que genera transformaciones en las prácticas pedagógicas, en el currículo escolar y en los espacios de enseñanza y aprendizaje. En este escenario, la escuela abre posibilidades, para que además de las disciplinas obligatorias, también sean ofrecidas a los alumnos oportunidades de conocer, discutir y reflexionar sobre diversas temáticas, entre ellas está la Educación Ambiental Patrimonial. Por lo tanto, el objetivo de este trabajo es discutir cómo la educación integral posibilita el desarrollo paradigmático y práctico de la educación

\footnotetext{
${ }^{1}$ Artigo apresentado no Simpósio Temático ST 04- Políticas públicas, diversidade cultural e descolonização durante o II Seminário Latino-Americano de Estudos em Cultura - SEMLACult em Foz do Iguaçu/PR, Brasil, 2018. O presente trabalho foi realizado com o apoio da Coordenação de Aperfeiçoamento Pessoal de Nível Superior- Brasil (CAPES)-Código de Financiamento 001. Agradecimentos ao Instituto Federal do Amapá (IFAP).

${ }^{2}$ Doutoranda em Educação (PUC/PR); Pontifícia Universidade Católica do Paraná; Curitiba, Paraná, Brasil; celia.amapa@hotmail.com
} 
ambiental patrimonial. De este modo, la metodología utilizada fue la investigación cualitativa de cuño bibliográfico, documental exploratorio y de análisis reflexivo. Para conceptualizar y reflexionar sobre la educación ambiental patrimonial fueron elegidos los autores Florêncio et al. (2014), Florêncio (2015) y Riffel (2017). En el ámbito de la educación integral, analizamos documentos oficiales del Ministerio de Educación y Cultura (MEC) y contextualizamos esas informaciones con el aporte teórico presentado por Pestana (2014) y Pinho y Peixoto (2017). Además, la investigación resalta la importancia de la educación ambiental patrimonial en el contexto escolar que desempeña un papel fundamental en la construcción de un individuo social y ambiental, pues es por medio de actividades específicas de la educación ambiental patrimonial que el alumnado perfecciona su identidad cultural, de pertenencia, de conservación y preservación de los bienes materiales e inmateriales que se constituyen como patrimonio cultural.

Palabras claves: Educación Ambiental Patrimonial; Espacios de Enseñanza y Aprendizaje; Educación Integral. Política Pública.

\begin{abstract}
Integral education is an educational public policy that has gradually been incorporated into Brazilian education, which generates transformations in pedagogical practices, in the school curriculum and in the teaching and learning spaces. In this scenario, the school opens possibilities, so that in addition to the obligatory subjects, students are also offered opportunities to meet, discuss and reflect on various themes, among them is Environmental Environmental Education. Therefore, the objective of this work is to discuss how integral education makes possible the paradigmatic and practical development of patrimonial environmental education. Thus, the methodology used was the qualitative research of a bibliographic, exploratory and reflective analysis. The authors Florêncio et al. (2014), Florêncio (2015) and Riffel (2017). Were elected in order to conceptualize and reflect on the patrimonial environmental education. In the context of integral education, we analyze official documents of the Ministry of Education and Culture (MEC) and contextualize this information with the theoretical contribution presented by Pestana (2014) and Pinho e Peixoto (2017). In addition, the research highlights the importance of patrimonial environmental education in the school context that plays a fundamental role in the construction of a social and environmental individual, since it is through specific environmental education activities that the student improves his cultural identity, issues of belonging, of conservation and preservation of the material and immaterial goods that constitute as cultural patrimony.
\end{abstract}

Keywords: Environmental Environmental Education; Teaching and Learning Spaces; Integral Education. Public policy.

\title{
1. Introdução
}

A Educação Ambiental Patrimonial (EAP) é um conceito em evolução e tem como intuito sensibilizar os indivíduos quanto à necessidade do cuidado, conservação, preservação e valorização do patrimônio cultural. Pois, a EAP possibilita o envolvimento da comunidade e desperta o sentimento de pertença, de identidade, requisitos fundamentais à convivência harmônica com os bens culturais, assim como para o repasse deste patrimônio às presentes e futuras gerações.

Neste sentido, a EAP se apresenta no ambiente escolar como um tema transversal que perpassa especialmente as disciplinas de Artes, História, Geografia, Filosofia e Sociologia, sendo uma temática que também é interdisciplinar. No viés da educação integral, o Programa Mais Educação surge para apoiar a ampliação do tempo dos discentes na escola e dentre as atividades propostas neste Programa está a EAP. 
Deste modo, o objetivo deste trabalho é discutir como a educação integral possibilita o desenvolvimento paradigmático e prático da educação ambiental patrimonial. Para isso, a metodologia utilizada foi a pesquisa qualitativa de cunho bibliográfico, documental exploratório e de análise reflexiva.

\section{Percurso metodológico}

Para Flick (2009, p.28), "o interesse pela abordagem qualitativa geralmente se concentra em desenvolver uma teoria a partir do material empírico e analisá-lo”. Creswell (2010, p. 206) diz que a pesquisa qualitativa é ampla, pois “[...] emprega diferentes concepções filosóficas; estratégias de investigação; e métodos de coleta, análise e interpretação de dados".

De acordo com Severino (2010, p.70), “a documentação bibliográfica constitui um acervo de informações sobre livros, artigos e demais trabalhos que existem sobre determinados assuntos, dentro de uma área do saber". A utilização das referências bibliográficas é importante para nortear o tema que está sendo discutido. Como assegura Severino (2010, p.134) “[...] a escolha das obras deve ser criteriosa, retendo apenas aquelas que interessam especificamente ao assunto tratado".

Sobre a pesquisa documental, Gil (2010, p.30) explica que este tipo de investigação é realizada de forma ampla em todas as ciências sociais e se aproxima da pesquisa bibliográfica, a diferença é que "a pesquisa documental vale-se de toda sorte de documentos, elaborados com finalidades diversas, tais como assentamento, autorização, comunicação, etc”. Gil (2010, p.59) complementa que a leitura exploratória tem como objetivo "verificar em que medida a obra consultada interessa à pesquisa".

Neste ínterim, a análise reflexiva se embasa em Gray (2012, p.403) que diz "a reflexidade envolve o entendimento de que o pesquisador não é um observador neutro, estando implicado na construção do conhecimento". Nesta perspectiva, a análise reflexiva busca discutir o tema estudado, especialmente sobre os conceitos e despertar em outros pesquisadores o desejo de conhecer mais sobre o assunto, com o objetivo de contribuir para a tessitura epistemológica.

\section{Educação Integral e o Programa Mais Educação na Escola}

Historicamente no Brasil, Pestana (2014) afirma a educação integral é citada pela primeira vez como política pública no Manifesto dos Pioneiros em 1932. A partir daí a educação integral foi se constituindo enquanto política educacional. Segundo Pinho e Peixoto 
(2017, p. 197, 198) “o conceito de Educação Integral vem ganhando cada vez mais espaço em debates públicos, como proposta educacional para o país, na busca pelo desenvolvimento pleno de indivíduos em suas diferentes dimensões".

Para Pestana (2014) na atual conjuntura da educação brasileira, a educação integral caminha para a vertente contemporânea que se constitui por políticas públicas sociais como ações e programas integradas com a ampliação da permanência do aluno na escola. Sendo que, a concepção contemporânea da educação integral está voltada à proteção social do indivíduo.

Atualmente, Pinho e Peixoto (2017, p.199) vislumbram o fortalecimento da educação integral com o surgimento da Lei de Diretrizes e Bases da Educação Nacional (LDBEN 9394/96) como um documento pautado pela "flexibilidade quanto à organização do ensino público, a lei que rege a educação brasileira aponta como horizonte da política educacional o aumento progressivo da jornada escolar [...]. Além disso, Pinho e Peixoto afirmam que "a LDB, outras leis (ECA) e a própria Constituição compõem a legislação que dispensam atenção no sentido de fortalecer a concepção da educação como direito social fundamental".

No que concerne a concepção de educação integral, para o Ministério da Educação e Cultura (MEC, 2018) se trata de "opção por um projeto educativo integrado", no qual os estudantes "são vistos como cidadãos de direitos em todas as suas dimensões". Isso significa que abrange o desenvolvimento intelectual, físico, da saúde, afetivo, ético e cultural "para que desfrute e produza arte, conheça e valorize sua história e seu patrimônio cultural, tenha uma atitude responsável diante da natureza, aprenda a respeitar os direitos humanos [...]”.

Neste sentido, é importante evidenciar que a educação brasileira aderiu a concepção contemporânea, tanto que Programa Mais Educação foi criado pela Portaria Interministerial $n^{\circ}$ 17/2007 e regulamentado pelo Decreto 7.083/10. Cita o documento que "constitui-se como estratégia do Ministério da Educação para induzir a ampliação da jornada escolar e a organização curricular na perspectiva da Educação Integral” (MEC, 2018).

Para integrar o Programa Mais Educação, as escolas públicas deveriam assinar o termo de adesão até o ano de 2014 por meio do site do Programa Dinheiro Direto na Escola (PDDE Interativo). De acordo com o Manual Operacional da Educação Integral (MEC, 2014), as atividades formativas oferecidas são divididas por macrocampos.

Em 2016, o MEC criou o Programa Novo Mais Educação por meio da Portaria n¹1.144/2016, reconhecida pela Resolução FNDE n5/2016. Este novo programa "É uma estratégia do Ministério da Educação para melhorar a aprendizagem em língua portuguesa e matemática no ensino fundamental, por meio da ampliação da jornada escolar de crianças e 
adolescentes" (MEC, 2018). Além das atividades com acompanhamento pedagógico em língua portuguesa e matemática, também foram inseridas atividades nos macrocampos de artes, cultura, esporte e lazer, impulsionando a melhoria do desempenho educacional mediante a complementação da carga horária de cinco ou quinze horas semanais no contraturno escolar, dentre estas atividades está a Educação Patrimonial.

\section{Educação Ambiental Patrimonial: uma possibilidade educativa na educação integral}

A Educação Ambiental Patrimonial, mais conhecida como Educação Patrimonial, segundo Marchette (2016, p.89) "é um processo de aprendizagem que se realiza mediante a utilização dos bens culturais, de natureza material e imaterial, como recursos educacionais". Essa atividade educativa "permite aproximar a sociedade do patrimônio cultural que a representa simbolicamente, promovendo a ampliação do entendimento da história passada e presente".

Conforme Florêncio (2015, p.24) "a Educação Patrimonial deve ser tratada como um conceito basilar para a valorização da diversidade cultural, para a definição de identidades e de alteridades [...] para a afirmação das diferentes maneiras de ser e de estar no mundo". A Educação Ambiental Patrimonial se apresenta como um ato de resistência, "evidencia a visibilidade de culturas marginalizadas ou excluídas [...] e que são fundamentais para o estabelecimento de diálogos interculturais e de uma cultura de tolerância com a diversidade".

Para Riffel (2017, p.49,50), a educação ambiental patrimonial "tem um papel decisivo no processo de preservação e valorização do patrimônio cultural, pois ela possibilita extrapolar as usuais abordagens acerca da preservação do patrimônio”. Isso significa que os sujeitos que convivem com estes patrimônios devem estabelecer "relações efetivas de conhecimento e preservação de suas práticas culturais".

Não se trata de uma tarefa fácil, mas possível de ser praticada, pois Riffel (2017, p. 50) menciona que "a preservação dos bens culturais deve consistir em práticas sociais que precisam estar inseridas nos contextos culturais e nos espaços de vida das pessoas". Porém, é fundamental que as pessoas ressignifiquem esses bens, que os reconheçam como parte do cotidiano, possibilitando momentos formativos, como na educação formal via contexto escolar.

Foi neste sentido de aproximar a escola do patrimônio cultural que o Instituto do Patrimônio Histórico e Artístico Nacional (IPHAN) estabeleceu uma parceria com o MEC. Florêncio et al. (2014, p.29) explicam que a política de Educação Patrimonial do IPHAN está estruturada em três eixos de atuação: Inserção do tema Patrimônio Cultural na educação 
formal; Gestão compartilhada das ações educativas; e Instituição de marcos programáticos no campo da Educação Patrimonial.

A educação formal, segundo Gohn (2006, p.2) se constitui enquanto "espaços do território das escolas, são instituições regulamentadas por lei, certificadoras, organizadas segundo diretrizes nacionais". Além dos mais, a "educação formal requer tempo, local específico, pessoal especializado". Também necessita de "uma organização de vários tipos (inclusive a curricular), sistematização sequencial das atividades, disciplinamento, regulamentos e leis, órgãos superiores etc [...], divide-se por idade/ classe de conhecimento", é a escola que conhecemos.

É na educação formal, no espaço escolar historicamente estabelecido por uma série de critérios e normas que surge o Programa Mais Educação (2007) criado pelo MEC, que em 2011 lançou o livro Programa Mais Educação Passo a Passo. Segundo este livro, o Programa Mais Educação é uma “estratégia promove a ampliação de tempos, espaços, oportunidades educativas e o compartilhamento da tarefa de educar entre os profissionais da educação e de outras áreas, as famílias e diferentes atores sociais [...]” (MEC, 2011, p.6).

Na primeira fase do Programa Mais Educação (2007) a Secretaria de Educação Básica (SEB) via Programa Dinheiro Direto na Escola (PDDE) disponibilizado pelo Fundo Nacional de Desenvolvimento da Educação (FNDE) elegiam escolas que apresentavam baixo índice de rendimento por meio do Sistema Integrado de Monitoramento do Ministério da Educação (SIMEC) para que fossem contemplados pelo Programa Mais Educação visando a ampliação da jornada escolar e a melhoria do rendimento dos alunos, com os seguintes macrocampos:

“1. Acompanhamento Pedagógico 2. Educação Ambiental 3. Esporte e Lazer 4. Direitos Humanos em Educação 5. Cultura e Artes 6. Cultura Digital 7. Promoção da Saúde 8. Comunicação e Uso de Mídias; 9. Investigação no Campo das Ciências da Natureza 10. Educação Econômica" (MEC, 2011, p.8).

No entanto, a educação patrimonial ainda não tinha conquistado grande espaço no Programa Mais Educação, isso somente aconteceu somente em 2011. Quando se estabeleceu a parceria entre o IPHAN e o MEC, "a Educação Patrimonial passou a integrar o macrocampo Cultura e Artes, na ocasião do II Encontro Nacional de Educação Patrimonial - II ENEP, realizado em Ouro Preto (MG), em julho de 2011” (IPHAN, 2014, p.33).

A partir da inclusão da Educação Patrimonial no Programa Mais Educação, para apoiar as atividades teóricas e práticas na escola, o IPHAN produziu uma série de materiais, dentre eles estão o livro Educação Patrimonial para o Programa Mais Educação (2011); 
Educação Patrimonial: manual de aplicação do Programa Mais Educação (2013); Fichas de inventário (2013).

A partir da experiência do Programa Mais Educação, o MEC revisou essa política pública educacional e lançou em 2016 o Programa Novo Mais Educação com o objetivo de "melhorar a aprendizagem em Língua Portuguesa e Matemática no ensino fundamental, por meio da ampliação da jornada escolar [...],mediante a complementação da carga horária de cinco ou quinze horas semanais no turno e contra turno escolar (MEC, 2018).

Apesar do enfoque maior do Programa Novo Mais Educação estar voltado para o ensino de português e matemática, a política educacional manteve o desenvolvimento de atividades nas áreas de cultura, artes, esportes e lazer. Dentre as atividades está a educação patrimonial. O Caderno de Orientações Pedagógicas versão II do Programa Novo Mais Educação (2018, p.50) diz que alguns materiais podem ser adquiridos para dar suporte as atividades escolhidas, levando em consideração as atividades eleitas no plano escolar.

No campo de cultura e artes, a educação patrimonial pode adquirir os seguintes materiais: "aquisição de material para confecção dos diferentes produtos realizados pelos estudantes (exposição, cartazes, pinturas, etc.); cartucho colorido de impressora ou serviço de impressão; fichários; serviço de transporte dos estudantes para saídas de campo" (MEC,2018,p.50).

Enfim, a política pública educacional Programa Mais Educação foi um passo importante para a inserção do eixo educação patrimonial no contexto escolar brasileiro. Mediante toda a trajetória da educação patrimonial, com a gerência do IPHAN, com o apoio de pesquisadores da área, monitores, educadores ambientais patrimoniais foi possível que a educação patrimonial ganhasse visibilidade na vertente da educação integral ao ponto de integrar o rol de atividades disponibilizados pelos macrocampos dos Programas Mais Educação (2007/2016) com intuito de se firmar na educação formal.

\section{Conclusões}

A Educação Ambiental Patrimonial (EAP) necessita ser difundida em toda a sociedade, especialmente nos âmbitos da educação, formal, informal e não-formal. No contexto da educação formal, a inserção da educação patrimonial como um macrocampo integrante do Programa Mais Educação (2007) e mais tarde no Programa Novo Mais Educação (2016) foi uma conquista. Assim, este trabalho contribui para a difusão desta temática, especialmente para o compartilhamento epistemológico do termo EAP. 
Como resultados, a EAP surge com o objetivo de empoderar e despertar a comunidade para o cuidado, preservação e conservação dos bens patrimoniais, pois o sentimento de pertença é formado a partir do momento que a temática patrimonial envolve afetivamente e socialmente os sujeitos. Quanto as limitações, a EAP ainda é um termo em construção, há autores que a intitulam como Educação Patrimonial (EP) e Educação Patrimonial Ambiental (EPA), portanto é um campo fértil para o desenvolvimento de termos que convergem para um único objetivo: educar para a valorização, preservação e conservação do patrimônio cultural.

É necessário salutar, o quanto a educação integral tem contribuído para que educação ambiental patrimonial seja conhecida e praticada no âmbito da educação formal. A partir desta constatação, se torna importante que os investigadores das mais diversas áreas pesquisem sobre iniciativas que envolvam a EAP, com o objetivo de socializar iniciativas práticas sobre a questão ou até mesmo ampliar a discussão sobre os termos empregados voltados à educação patrimonial.

\section{Referências}

CRESWELL, J. W. Projeto de pesquisa: métodos qualitativo, quantitativo e misto. Tradução Magda Lopes. Porto Alegre: Artmed, 2010. 296 p.

FLICK, U. Qualidade na pesquisa qualitativa. Tradução Roberto Cataldo Costa. Porto Alegre: Artmed, 2009. 191 p.

FLORÊNCIO, S.R.R. Educação Patrimonial: algumas diretrizes conceituais. In: PINHEIRO, A.R.S. (Org.). Cadernos do Patrimônio Cultural: educação patrimonial. Fortaleza: Seculfor/IPHAN, 2015. p. 21-30.

FLORÊNCIO, S.R.R. et al. Educação Patrimonial: histórico, conceitos e processos. Brasília: IPHAN,2014. 65 p.

GIL, A.C. Como elaborar projetos de pesquisa. São Paulo: Atlas,2010. 184 p.

GOHN, M.G. Educação não-formal na pedagogia social. In: CONGRESSO INTERNACIONAL DE PEDAGOGIA SOCIAL, 1., 2006, São Paulo. Anais do I Congresso Internacional de Pedagogia Social. São Paulo, 2006.

GRAY, D.E. Pesquisa no mundo real. Tradução Roberto Cataldo Costa. Porto Alegre: Penso,2012. $486 \mathrm{p}$.

Instituto do Patrimônio Histórico Artístico Nacional (IPHAN). Educação Patrimonial: histórico, conceitos e processos. Brasília: IPHAN, 2014.62 p. 
PESTANA, S.F.B. Afinal, o que é educação integral? Revista Contemporânea de Educação, v. $9, \quad$ n. 17, p.24-34, jan./jun.2014. ISSN 1809-5747. Disponível em:https://revistas.ufrj.br/index.php/rce/article/viewFile/1713/1562.Acesso em: 15 jul. 2018.

PINHO, M.J.; PEIXOTO, E.R.B. A educação integral diante do novo paradigma: perspectivas e desafios. Revista Educação e Linguagens, v. 6, n. 10, p. 197-216, jan./jun. 2017.

ISSN

2238-6084.

Disponível em:http://www.fecilcam.br/revista/index.php/educacaoelinguagens/article/viewFile/1293/90. Acesso em: 16 jul. 2018.

Ministério da Educação e Cultura (MEC). Educação Integral. Disponível em: http://educacaointegral.mec.gov.br/. Acesso em: 15 julho 2018.

—. Programa Mais Educação: passo a passo. 2011.Disponível em:http://portal.mec.gov.br/index.php?option=com_docman\&view=down \%20load\&alias=8 168 epassoapassomaiseducacao $18042011 \mathrm{pdf} \&$ category_slug=junho2011\%20pdf \&Itemid $=30$ 192. Acesso em: 15 dezembro 2018.

Histórico-Mais Educação. Disponível em:http://portal.mec.gov.br/apresentacao-sp778261474/116quemequem 1534541290/sebeducacaobasica2024241802/41181\%20historico -mais-educacao. Acesso em: 15 julho 2018.

Manual Operacional de Educação Integral. 2014. Disponível em:http://educacaointegral.mec.gov.br/link-de-noticias/33-manual-operacional-de-educacaointegral-2014. Acesso em: 15 julho 2018.

Programa Novo Mais Educação: caderno de orientações pedagógicas versão II.2018.Disponível em: http://portal.mec.gov.br/index.php?option=com_docman\&view=download\&alias=90251 cad erno-orientador-pnme\&category slug=junho-2018-pdf\&Itemid=30192. Acesso em: 15 julho 2018.

Programa Novo Mais Educação. Disponível em:http://educacaointegral.mec.gov.br/historico-mais-educacao. Acesso em: 15 julho 2018.

RIFFEL, R. Educação Patrimonial e os processos educativos: referências culturais como espaços de ensino-aprendizagem na educação básica. Revista História UNICAPUniversidade Católica de Pernambuco, [S.1.], v. 4, n. 07, p. 47-59, jan./jun 2014. ISSN 2359-2370.Disponível em:http://www.unicap.br/ojs/index.php/historia/article/view/968/897. Acesso em: 15 dez. 2018.

SEVERINO, A.J. Metodologia do trabalho científico. 23.ed. rev. e atual. São Paulo: Cortez, 2010. 302 p. 